\title{
İlkokul Fen Bilimleri Ders Kitaplarında Yer Alan Kültürel Ögelerin İncelenmesi
}

\section{Examination of Cultural Elements in Primary School Science Textbooks}

\author{
M. Fatih GÜVENDİ, Sorumlu Yazar, Doktora Öğrencisi. \\ Marmara Üniversitesi Eğitim Bilimleri Enstitüsü, İstanbul/Türkiye. \\ fatihguvendi@marun.edu.tr \\ https://orcid.org/0000-0002-3355-040X
}

ISSN: 1303-880X

e-ISSN: 2667-7504

http://ded.dem.org.tr

Makale Türü / Article Type:

Araştırma Makalesi / Research Article

Geliş Tarihi / Received Date: 11.03.2021

Kabul Tarihi / Accepted Date: 09.08.2021

Yayın Tarihi / Published Date: 25.12.2021

Tr/En: $\operatorname{Tr}$

Intihal / Plagiarism: Bu makale, en az iki hakem tarafindan incelendi ve intihal içermediği teyit edildi. / This article has been reviewed by at least two referees and scanned via a plagiarism software.
Atıf/Citation: Güvendi, M.F. (2021). İlkokul fen bilimleri ders kitaplarında yer alan kültürel ögelerin incelenmesi. Değerler Ĕgitimi Dergisi, 19 (42), s. 9-37

https://doi.org/10.34234/ded.895236 
Öz: Bu araştırmada, ilkokul fen bilimleri ders kitaplarında yer alan kültürel ögelerin belirlenmesi amaçlanmıştır. Araştırmada, nitel araştırma yöntemlerinden doküman analizi kullanılmıştır. Verilerin analizinde fen bilimleri ders kitaplarında yer alan metinler, hikâyeler, görseller, biyografiler, olaylar, sanatlar, aletler, yapılar içerik analizine tabi tutulmuştur. Araştırmada, ilkokul 3. ve 4. sınıf fen bilimleri ders kitapları incelenmiştir. Ders kitaplarında yer alan kültürel ögeler, dokuz ana başlıkta sınıflandırılmış ve tablolaştırılmıştır. Araştırmada, MEB Yayınlarının hazırladığı ders kitaplarında daha fazla kültürel ögelere yer verildiği, "Gezegenimizi Tanıyalım” ile "Yer Kabuğu ve Dünya'mızın Hareketleri” ünitelerinin kültürel değerleri daha fazla içerdiği, literatürdeki araştırmaların aksine Türk-İslam bilim insanlarına ders kitaplarında çok az yer verildiği sonucuna ulaşılmıştır. Ulaşılan sonuçlara göre ilkokul fen bilimleri ders kitaplarında Türk-İslam bilim insanlarının görsellerine ve düşüncelerine daha fazla yer verilebileceği, ders kitaplarında kullanılan görsellerin ve ögelerin seçiminde yereli yansıtan ve Türk kültürüne daha yakın görsellerin seçilmesi önerilmiştir.

Anahtar Kelimeler: Fen Bilimleri, Ders kitabı, Kültür, Kültürel ögeler, Bilim insanlar1.

\section{\&}

Abstract: This research aims to determine the cultural elements in primary school science textbooks. In the research, document analysis, one of the qualitative research methods, was used. In the analysis of the data, the texts, stories, pictures, biographies, events, arts, tools, and structures in the science textbooks were subjected to content analysis. In the research, primary school 3rd and 4thgrade science textbooks were examined. The cultural elements in the textbooks are classified and tabulated under nine main headings. The research has shown that more cultural elements are included in the textbooks prepared by MEB Publications. It has been determined that the units "Let's Get to Know Our Planet" and "The Earth's Crust and the Movements of Our Earth" contain more cultural values. Contrary to the studies in the literature, it has been concluded that Turkish-Islamic scientists are given very little place in the textbooks. According to the results, it can be stated that the pictures and thoughts of Turkish-Islamic scientists can be given more place in primary school science textbooks. In addition, it has been suggested that the pictures and elements used in the textbooks should be chosen from the visuals reflecting the Turkish culture.

Keywords: Science, Textbook, Culture, Cultural elements, Scientists.

(The Extended Abstract is at the end of the article) 


\section{Giriş}

Eğitim, insanların bilişsel bilgi ve becerilerini geliştirmelerinin yanı sıra toplumsal değerlerin aktarılmasında da önemli misyon üstlenir (Acar ve Yaman-Kasap, 2020). Eğitim vasıtasıyla geçmişten alınan toplumsal değerler, günün ihtiyaçları da göz önünde bulundurularak gelecek nesillere aktarllır. Toplumsal değerlerin oluşumunda ve aktarımında geçmişten gelen maddi ve manevi kültürel miras belirleyici olmaktadır (Acar ve Yaman-Kasap, 2020; Gündüz vd., 2019). Kültürün maddi ve manevi olarak ayrılması (Turhan, 2002), kültürün yaşam biçimi olarak tanımlanmasından ileri gelmektedir (Varış, 1994) hatta bir milleti millet yapan tezahürlerin bütünü olarak görülmesinden kaynaklanır (Kaplan, 2010). Buna göre maddi kültür; bir toplumun yemekleri, giydiği eşyaları, kulland1$\breve{g} 1$ araç gereçleri, mimari yapısı, el sanatları ve benzeri bileşenlerinden oluşur. Kültürün manevi boyutu ise toplumun dini, dili, örf ve âdetleri, değer yargilar1, edebiyatı, sanatı, bilimi ve felsefesi olarak tanımlanmaktadır (Arslanoğlu, 2015). Her ne kadar Kongar (1982), edebiyat, sanat ve düşünce dünyasını bu sınıflandırmanın dışında tutsa da bunları kültürün önemli bileşenleri arasında saymaktadır. Diğer taraftan Güngör (1994) de kültürün bir inanç, bilgi, his ve heyecanlar bütünü olduğu savunmaktadır. Ayrıca maddi kültürün, kültürün kendisi olmadığını belirtmekte ve manevi kültürün ifade şekli olarak maddi kültürü görmektedir. Gadamer (1988) ise Güngör'ün (1994) tanımlamasının aksine kültürü, daha çok yaşam pratikleri üzerinden yani maddi kültür üzerinden yorumlamaktadır. Topçu (2013) da kültürü, toplumun kendi tarihî serüveni üzerinden okuyarak meydana getirdiği değer yargılarının bütünü olarak görmektedir. Diğer taraftan UNESCO ise Dünya Kültür Politikaları Konferansı Sonuç Bildirgesi'nde kültürü şöyle tanımlamaktadır; "en geniş anlamıyla kültür, bir toplumu ya da toplumsal bir grubu tanımlayan belirgin maddi, manevi, zihinsel ve duygusal özelliklerin bileşiminden oluşan bir bütün ve sadece bilim ve edebiyatı değil aynı zamanda yaşam biçimlerini, insanın temel haklarını, değer yargılarını, geleneklerini ve inançlarını da kapsayan bir olgu"dur (UNESCO, 1982).

Eğitimde kültürün aktarımının sağlanmasında ders kitaplarının belirleyiciliği yüksektir (Gülden, 2018). Ders kitaplarına yerleştirilecek kültürel ögelerin belirlenmesinde ve bunların kitaplara yerleştirilmesinde belli kriterlere dikkat edilmesi, kültürün sonraki nesillere aktarılmasında önemli görülmektedir (Akyüz, 2016). Kültürel ögelerin aktarımı konusunda literatürde sosyal bilgiler ve Türkçe ders kitaplarına yoğunlaşılması, bu derslerin kültür aktarımında kritik dersler olduğunu ortaya koymaktadır. Ancak fen bilgisi/bilimleri gibi toplu- 
mun ihtiyaçlarını, beklentilerini ve sorunlarını merkeze alarak yapılandırılan ders kitaplarının kültürel bağlamda ele alınmaması büyük bir eksikliktir. Ayrıca fen bilimleri dersinin teknoloji, toplum ve çevre bağlamının yüksek olması ve birçok bilimsel olay, olgu ve sürecin kültürle şekillenmesi bu dersi ön plana çıarmaktadır (Yalaki, 2014).

Ülkemizde fen bilimleri ders kitaplarının kültürel bağlamda incelenmesini içeren çalışma görülmemektedir. Bu çalışmanın da ana motivasyon kaynağını bu gerekçe oluşturmaktadır. Bu bağlamda bu çalışmanın amacı; ilkokul fen bilimleri ders kitaplarında yer alan kültürel ögeleri belirlemektir. Bu çalışmada ilkokul ders kitaplarının seçilmesinin nedeni ise Çengelci (2012) ile Pass ve arkadaşlarının (2006) da belirttiği üzere ilkokul yıllarının kültürel mirasın aktarılmasında ve kültürel farkındalığın oluşmasında önemli görülmesidir. Bu çalışmanın bir diğer özgün noktası, fen bilimleri ders kitaplarında yer alan kültürel ögeleri belirlemek amacıyla oluşturulan ve kültürel temaları içeren bir formun hazırlanmış olmasıdır. Bu husus, bundan sonraki çalışmalar için bir referans noktası oluşturması ve alana katkı sunması bakımından önem arz etmektedir.

\section{Kültür - Eğitim İlişkisi}

Eğitim, kültürün tespit edilmesinde, oluşturulmasında, geliştirilmesinde ve gelecek nesillere aktarılmasında kritik bir rol oynar (Sülün ve Balkı, 2008). Akyüz (2016), eğitimin kültürü oluşturan bireyleri yetiştirdiğine vurgu yaparak eğitimin hem geçmişten gelen kültürel mirası koruduğuna hem de insanın bulunduğu şartlara uygun biçimde yetiştirmeye olanak sağladığına dikkat çeker. Böylelikle eğitim, kültürün gelişmesinde, yeni nesillere aktarılmasında ve korunmasında önemli bir misyon üstlenir (Akyüz, 2016; Gretta, 2001).

Kültür çalışmalarında dikkat çeken önemli noktalardan biri, kültürün nesilden nesile aktarımı mevzusudur. Kültürün nesilden nesile nasıl aktarılacağı hususu, kültürün planlı ve amaçlı olarak gerçekleştirilmesini doğurmuş ve kültürleme olarak karşılık bulmuştur (Gün-Duru, 2013). Hatta bu bilinçli kültürleme, Demirel'de (2003) eğitime karşıllk gelmektedir. Bu bağlamda kültür ve eğitim birbirini besleyen iki bileşen olarak görülmektedir. Yani kültürel yaşamda meydana gelebilecek değişimler eğitimi, eğitim ortamında meydana gelebilecek değişimler de kültürü etkilemektedir (Şahin, 2019). Diğer taraftan bu toplumsal değişim ve dönüşüm ile eğitim arasında zit bir ilişki olabileceği de göze çarpmaktadır. Nitekim Erol (2011), eğitimin hem kültürel ögeleri koruyup sonraki nesillere aktarma misyonunu hem de değişime uygun bir formatta işlev gör- 
mesini birbirine zit iki durum olarak görmektedir. Erol'a (2011) göre değişen toplumlarda, değişen şartlara uyum sağlayacak ve toplumun ilerlemesine katkı sunacak bireyleri yetiştirmek, eğitimin yaratıcı yönünü ortaya koymaktadır.

Kültür aktarımında karşılaşılabilecek bir başka durum ise kuşaklar arası farklılaşmadan kaynaklanmaktadır. Eski kuşakların kendi kültürel yaşamlarını, sistemlerini, ideolojilerini, maddi ve manevi kültürel ögelerini yücelterek bunu sonraki nesillere dayatmaları, kuşaklar arası çatışmaların temelini oluşturur (Özdemir, 2019). Kuşaklar arası çatışmanın derinlikli olarak tartışılmadığını savunan Özdemir (2019), bu sorunun çözümünde önceki ve sonraki neslin birbirlerini anlama ve uyum sağlama yollarına bağlı olarak gerçekleşebileceğini belirtir. Bu uyumun sağlanmasında ise gerçekliğin ön planda tutulması, karş1lıklı anlayış ve iletişimin güçlenmesi, farkındalığın oluşması ve bilinç kazandırmanın önemine vurgu yapar. Demirel'in (2003) de belirttiği gibi bu kültürleme hareketi bilinçli olarak yapılırsa eğitim hâlini almış olur.

Kültürün eğitimi etkilediği ve tartışmaları da beraberinde getirdiği alanlarından biri çokkültürlülük meselesidir. Eğitimin özellikle kültürel mirası savunmak ve bunu sonraki nesillere aktarma işleviyle hareket etmesini isteyenler kadar kültürün insanlığın ortak mirası olduğunu savunarak eğitimi, farklı kültürleri öğrenmenin bir aracı olarak görenler de vardır. Bu iki kesimin argümanları neticesinde kültürel değerlere duyarlı eğitim gibi farklı anlayışlar da türemiştir. Kültürleme olarak belirtilen ve her gelenek, görenek, örf, âdet ve inanışın eğitime yansıtılması (Eroğlu ve Yaldız, 2006) gerektiğini belirtenlerin en önemli gerekçeleri; özellikle küreselleşme ile toplumsal değerlerin, yaşam tarzlarının ve geçmiş kültürlerin geleceğe aktarılamaması ve yok olmasıdır (Selanik-Ay ve Korkmaz, 2017). Bu görüşü savunanlara göre toplumun kimliği olan kültürün korunması için eğitime ciddi işler düşmektedir (Çengelci, 2012; Türkyılmaz, 2013). Diğer taraftan Bauman'a göre (2020) çok merkezli ve çokkültürlü bir dünyada yabancı kültürlerle ve farklı yaşam şartları ile yaşamayı öğrenmek ve bunu uygulamaya geçirmek hatta bunu daha da geliştirmek kaçınılmazdır. Bundan dolayı modern dönem eğitim sisteminin bilgi, beceri ve değer yargılar1 günümüz küresel yeterliklerini karşılayamamaktadır (İşeri, 2020). Hatta bu görüşü savunanlar, kültürün bireysel kimlik üzerinde bir varlığının ve etkisinin olmadığını iddia etmektedirler (Heine, 2008). Bu iki zıt görüşün aksine hem yerel kültürel değerlerin hem de küresel kültürel değerlerin birlikte verilmesi gerektiğini belirten görüşler son y1llarda daha çok gündem oluşturmaktadır. Bu bağlamda eğitimin eşitliği ve başarıyı sağlaması, ayrımcılıkları ortadan kaldır- 
mas1, eğitimde istenmeyen durumlarla mücadele etmesi, kültürel farklılıklara saygı ile gerçekleşebilmektedir (Kotluk ve Kocakaya, 2018). Bunu gerçekleştirebilmek için de kültürel farklılıkları dikkate alarak çokkültürlü eğitim, kültürel değerlere duyarlı pedagoji, öğretim ve eğitimin yaygınlaşması gerekmektedir (Kotluk ve Kocakaya, 2018). Bu yaklaşımı savunanlara göre eğitim, farklı kültürel değerleri çocuklara öğretirken aslında onların kültürel değerlerini daha iyi kavrayabilecekleri anlamını da taşımaktadır (Doğan, 2019).

Kültürel değerlerin aktarımında önemli hususlardan biri de kültür aktarımının ne zaman yapılacağı meselesidir. Bu bağlamda yapılan çalışmalar incelendiğinde çocuğun doğup büyüdüğü ve yetiştiği aile ortamının en önemli kültür aktarıcısı olduğu rahatlıkla ifade edilebilir (Gökçe, 1990). Aybey'in (2018) dinî değerlerin aktarılmasında ailenin rolünü araştırdığı çalışmasında, bu aktarımda ailenin dikkat etmesi gereken ilkeler şöyle sıralanmaktadır: Çocuğun gelişimine göre aktarım/zamanlama, sevgi gösterme, model olma, etkili iletişim geliştirme, ödül ve ceza yöntemini kullanma, hikâye ve masallardan yararlanma, uygun zaman ve ortamı yakalama. Bu dinî değerlerin kültürel değerleri de içerdiği düşünülürse kültürel aktarımda da kullanılabileceği ifade edilebilir. Ayrıca kültürel aktarımlarda tarihî şahsiyetlerden yararlanma, şekil ve sembolleri kullanma, sanatsal ürünlerden faydalanma gibi farklı kültürel ögelerden de yararlanılabilir.

Kültürel aktarımda okul öncesi eğitimin ve aile katılımının çocukların kültürel yeterliklerini geliştirdiğine dair olumlu çalışmalar bulunmaktadır (Şahin ve Kalburan, 2009; Toran ve Özgen, 2018). Bununla beraber okul öncesi gerçekleştirilecek bu eğitimlerle farklı kültürlerden gelen çocukların birlikte hemhâl olmalarına ve birbirlerini anlamalarına ve saygı göstermelerine daha erken yaşlarda başlayabilecekleri imkânı tanınmış olmaktadır. Pass ve arkadaşları (2006) ise çocukların ilkokula başladıklarında bu kültürel farklılıkların bir zenginlik olduğunu ve bunlara karşı1ık bir farkındalık geliştirmenin önemli olduğunu belirtmişlerdir. Aynı zamanda ders kitaplarında ve öğretim programlarında çokkültürlülüğü yansıtacak bir kültürlemenin sağlanması gerektiğini ifade etmişlerdir.

\section{Ders Kitaplarında Kültürel Ögeler}

Okullar, öğrencilere akademik bilgi ve beceri kazandırmanın yanı sıra kültürel mirası aktarma, toplumsal kalkınmaya aracılık etme ve bireyin sosyalleşmesi gibi birçok işlevi yerine getirmektedir (Ergin ve Çayak, 2019). Okulların bunu gerçekleştirebilmeleri için kendilerine rehber olabilecek bir öğretim programına ihtiyaçları vardır. Bu bağlamda öğretim programları; toplumsal, tarihî, felse- 
fi, psikolojik ve ekonomik temeller ön planda tutularak hazırlanır (Fer, 2019). Bundan dolayı eğitimin tüm bu alanlarla ve bu alanların da eğitimle ilişkisi bulunur. Eğitimin kültürden kültürün de eğitimden etkilenmesi ve birbirlerini etkilemeleri de kaçınılmazdır. Çünkü kültür toplumsal hayatı, toplumsal hayat da kültürü etkilemektedir (Ültanır, 2003). Sonuç olarak toplumsal hayatı etkileyen bütün olaylar, kültürü ve eğitimi etkilemektedir.

Ülkemizde ders kitapları ve kültür bağlamında yapılan çalışmalar incelendiğinde genellikle sosyal bilgiler kitaplarının ele alındığı görülmektedir (Pehlivan ve Kolaç, 2016; Gürel ve Çetin, 2018; Daşdemir ve Tekin, 2018; Ünlüer, 2018; Sağ, 2018; Ateş vd., 2018). Sosyal bilgiler dersinin özellikle kültür ve kültür bağlamı çalışmalarında ele alınması, kültürleme görevinin sosyal bilgiler dersine bırakılmasından kaynaklıdır (Safran, 2008). Ayrıca sosyal bilgiler dersinin kültürel mirası aktarabilecek en rahat derslerinden biri olarak görülmesinden dolayıdır (Ünlüer, 2018). Millî Eğitim Bakanlığı'nın hazırladığı 2018 yılı Sosyal Bilgiler Dersi Öğretim Programında “Kültür ve Miras" konulu başlı başına bir öğrenme alanı olması bunu desteklemektedir (MEB, 2018).

Sosyal bilgiler ve kültür içerikli çalışmalar incelendiğinde somut olmayan kültürel miras ögelerinin önemli bir yer tuttuğu görülmektedir (Çengelci, 2012; Dönmez ve Yeşilbursa, 2014; Pehlivan ve Kolaç, 2016). Somut olmayan kültürel miras ögeleri olarak (i) sözlü gelenekler ve anlatımlar, (ii) gösteri sanatları, (iii) toplumsal uygulamalar, ritüeller ve şölenler, (iv) doğa ve evrenle ilgili bilgi ve uygulamalar, (v) el sanatları geleneği fazlaca yer tutmaktadır. Bunların haricinde spesifik olarak atasözleri (Sönmez, 2014), müzeler (Egüz ve Kesten, 2012; Meydan ve Akkuş, 2014), edebî eserler, şarkılar, hikâyeler (Demir ve Akengin, 2014; Öztürk vd., 2014; Ünlüer, 2018) üzerine yapılmış araştırmalar da bulunmaktadir.

Fen bilimleri bağlamında ise kültürel içerikli çalışmaların varlığı sınırlıdır. Kotluk'a (2018) göre bunun sebepleri arasında fen ve matematik konularının daha çok sayısal olması ve formüllerle ifade edilmesi, öğretmenlerin bilim ile kültürü birbirinden ayrı şeyler olarak görmeleri ve bu derslerin pozitivist bir bakış açısıyla hazırlanmış olmaları etkilidir. Buna ek olarak Laçin-Şimşek (2011a) yaptığı bir çalışmada, öğretmenlerin fen derslerinde bilim insanlarından ve bilim tarihinden sadece bilimsel bilgi aktarmak noktasıyla faydalandıkları aslında bilimsel çalışmaların nasıl yapıldığı ve bunların hangi koşullarda gerçekleştirildiği noktasında eksik kalındığını belirtmektedir. Bilimsel araştırmaların toplumları, kültürleri, ekonomik faaliyetleri nasıl etkilediği üzerinde ise durul- 
madığını ifade etmektedir (Laçin-Şimşek, 2011a). Bilimsel araştırmalar, bir toplumun tarihsel gelişimi ve toplumsal hayatıyla ilişkili olduğundan kültürden bağımsız oldukları düşünülemez (Sülün ve Balk1, 2008). Sarıtaş (2020) ise bu olaya farklı bir bağlamda yaklaşarak sosyal bilgiler derslerinde verilen bilim insanları ve bilim tarihi örneklerinin fen bilimleri ders kitaplarından daha fazla olduğunu dile getirmekte ve bunun sosyal bilimlerin bir ürünü değil fen bilimlerinin tarihi ve burada çalışan bilim insanlarının ürünleri olarak görmektedir.

Sülün ve Balkı (2008), fen bilimlerinde kültürü; aile, arkadaş, çevre ile ilişkilerin bir bütünü olarak tanımlar. İlk olarak bu birlikteliğin 1970'li y1llarda savunulmaya başladığı ve Fen-Teknoloji-Toplum temelinde şekillendiği sonrasında ise buna çevrenin de eklenmesiyle Fen-Teknoloji-Toplum-Çevre olarak günümüze taşındığı görülmektedir (Karışan, 2017). FTTÇ’nin amacı; bireylerin günlük hayatta karşılaştıkları olayları bilimsel bir perspektifle açıklayabilme, olayları çok yönlü değerlendirebilme, sosyal, kültürel ve etik ile ilgili konularda sorumlu davranabilme ve bilinçli karar verebilme davranışlarını geliştirmektir (Yalaki, 2014). Tüm bu bağlamlardan bakıldığında da Fen Bilimleri derslerinin ve öğretim programlarının bir kültür aktarım sürecini gerçekleştirdiğini söylemek mümkündür (Sülün ve Balk1, 2008). Buna ek olarak Kotluk ve Kocakaya (2018), kültür aktarımının sadece sosyal bilgiler dersi ile sınırlı olmayacağını belirtmesi de bu iddiayı güçlendirmektedir.

Fen bilimleri eğitimi ve kültür arasındaki çalışmalara vurgu yapan sınırlı sayıda kaynak bulunmaktadır (Gürses vd., 2004; Sülün ve Balk1, 2008; Sar1taş, 2020). Bu çalışmalar incelendiğinde bilimin ve bilimsel bilginin kültürel temellerine vurgu yapılmakta ve kültür bilim ilişkisinde sağduyuyla hareket edilmesinin önemi belirtilmektedir (Gürses vd., 2004). Bunun yanı sıra Sülün ve Balkı (2008) da fen ve teknoloji eğitiminin toplumun kendi dinamiklerini dikkate alarak ve kültürüyle bütünleşik bir şekilde yapılması gerektiğini ifade etmektedir. Sarıtaş (2020) ise fen bilimleri dersi öğretim programı üzerinden hazırladığı çalışmasında kültürü, bilim ve bilim insanları üzerinden okumuştur. Ona göre evrensel ve yerel bağlamda geliştirilebilecek bir bilim-kültür ilişkisi, sosyal bilgiler dersi kadar fen bilimleri dersleri için de geçerlidir.

Fen bilimlerinin kültürel bağlamına yönelik yapılan çalışmaların odak noktaS1, bilim tarihi ve bilim insanları üzerine yoğunlaşmaktadır (Baş, 2019; Bozdoğan vd., 2013; Görecek-Baybars, 2018; İdin ve Yalaki, 2016; Kardaş ve Şahin, 2020; Koçyiğit ve Pektaş, 2017; Laçin-Şimşek, 2009; Laçin-Şimşek, 2011b). Bu çalışmalardan bazıları fen bilgisi öğretmen adaylarının bilim insanları hak- 
kında bilgi ve farkındalık düzeylerinin incelenmesine odaklanmaktadır (Baş, 2019; Bozdoğan vd., 2013; Görecek-Baybars, 2018). Bazıları ise fen bilimleri ders kitaplarında yer alan Türk-İslam bilim insanlarının incelenmesine yer vermektedir (İdin ve Yalaki, 2016; Laçin-Şimşek, 2011b). Kardaş ve Şahin'in (2020) çalışması ise bilimsel hikâyelere, Koçyiğit ve Pektaş'ın (2017) çalışması da okuma metinlerine odaklanmaktadır.

Fen bilimleri ders programlarında ve ders kitaplarında bilimsel şahsiyetlere odaklanmanın kültürel arka planı olduğunu görmek önem arz etmektedir. Fazlığlu (2004) da bunu bilim tarihi bağlamında şu şekilde ifade etmektedir: “... bilim tarihi disiplininin, bilimin ne olduğu, kökeni, gelişimi, bilime katkı yapan kişilerin hayatı, bilimsel kurumlar ve âletler, bilimin iktisadî, siyasî, dinî ve toplumsal bağlamla ilişkisi, bilimsel bilginin farklı kültürler arasında aktarımı vb. konuları incelediği söylenebilir." Bu bağlamda rahatlıkla ifade edilebileceği üzere ders kitaplarında yer alan bilim insanlarının bulundukları tarih ve çevre içinde incelemek ve okumak gerekmektedir. Fazlıoğlu'nun (2004) da ifade ettiği üzere anlaşılmaktadır ki tek bir bilim değil bilimlerden söz etmek gerekmektedir. Yunanistan'da fen bilimleri ders kitaplarında bilim insanlarının daha çok yer bulmasının temel sebebini araştıran Drakopoulou ve arkadaşları (2005), öğrencilerin bilimsel konuları daha rahat anlamalarına, bilimsel yöntem ve basamakları öğrenmeye yardımcı olmalarına ve öğrencileri motive etmelerine bağlamışlardır.

Fen bilimleri ders kitapları bağlamında literatür incelendiğinde kültürel bağlamı genel olarak yansıtan çalışma bulunmamaktadır. Bu bağlamda Fen Bilimleri ders kitaplarındaki kültürel ögeleri belirleyecek bir sınıflandırma ihtiyacı da ortaya çıkmaktadır. Bu sınıflandırmayı gerçekleştirebilmek amacıyla hem literatürde kültürel ögeleri belirleyecek çalışmalar incelenmiş hem de ders kitapları bağlamında çocuklara verilebilecek kültürel ögeler belirlenmeye çalış1lmıştır. Ders kitaplarında kullanılan kültürel ögeleri literatür çerçevesinde değerlendirdiğimizde Özkan-Köse ve Yüksel (2019) ile Pehlivan ve Kolaç'ın (2016) ça1ışmaları somut olmayan kültürel miras ögeleri bağlamında referans alınmıştır. Bu çalışmalar, UNESCO'nun belirlediği Somut Olmayan Kültürel Miras (SOKÜM) referans alınarak hazırlanmıştır (UNESCO, 2020). UNESCO Somut Olmayan Kültürel Miras alanları 5 ana başlıkta verilmiştir. Bunlar; "Sözlü Gelenekler ve Anlatımlar", "Gösteri Sanatları”, "Toplumsal Uygulamalar, Ritüeller ve Şölenler”, "Doğa ve Evrenle İlgili Uygulamalar", "El Sanatları Geleneği”. Ancak Özkan-Köse ve Yüksel ile (2019) Pehlivan ve Kolaç’ın (2016) çalış- 
maları, sosyal bilgiler ve müzik ders kitapları üzerinden gerçekleştirildiği ve sadece somut olmayan kültürel ögeleri içerdiği için Fen Bilimleri ders kitapları bağlamında kuşatıcı görünmemektedir. Bu bağlamda Fen Bilimleri ders kitaplarında kültürel ögeleri belirleyecek ve hem literatür hem de UNESCO kriterlerini de kapsayacak şekilde fen bilimleri özelinde 9 ana başlık belirlenmiştir. $\mathrm{Bu}$ başlıklar "Yerel Yapılar ve Kurumlar", "Farklı Kültürlere Ait Yapılar ve Kurumlar", "Yabancı Bilim İnsanları ve Düşünceleri”, "Türk-İslam Bilim İnsanları ve Düşünceleri”, "El Sanatları", "Aletler, Araç-Gereçler”, "Dinî İnançlar, Semboller ve Değerler", "Sözlü Gelenek ve Anlatımlar" ve "Kültürel Yiyecekler, İçecekler" başlıkları altında incelenmiştir. Bu başlıklarda, "Yerel Yapılar ve Kurumlar", "Farklı Kültürlere Ait Yapılar ve Kurumlar"1n olması, somut kültürel ögelerin de ders kitaplarında incelenmesini gerektirmesinden dolayıdır. Yine bu başlıklandırmalarda yerel ve yabancı ayrımının yapılması, karşıllaştırma yapılmasına imkân tanıması dolayısıyladır. Diğer taraftan özel olarak dinî konulara referans olabilecek hususların belirlenmesi amacıyla "Dinî İnançlar, Semboller ve Değerler" başlığı eklenmiş ayrıca fen bilimleri için önemli konu başlıkları arasında yer alan ve kültürel değerleri de içerebilecek "Yabancı Bilim İnsanları ve Düşünceleri”, "Türk-İslam Bilim İnsanları ve Düşünceleri” ile "Kültürel Yiyecekler, İçecekler" başlı̆̆ 1 da eklenmiştir. Bunun haricinde "El Sanatları" ile "Sözlü Gelenek ve Anlatımlar" somut olmayan kültürel ögeler olarak çalışmada yer almıştır.

Literatür incelemelerinden de anlaşılacağ 1 üzere ülkemizde fen bilimleri ders kitaplarının kültürel bağlamda incelenmesini içeren çalışma görülmemektedir. $\mathrm{Bu}$ çalışmanın da ana motivasyon kaynağını bu gerekçe oluşturmaktadır. Bu bağlamda bu çalışmanın amacı; ilkokul fen bilimleri ders kitaplarında yer alan kültürel ögeleri belirlemektir. Bu çalışmada ilkokul ders kitaplarının seçilmesinin nedeni ise Çengelci (2012) ile Pass ve arkadaşlarının (2006) da belirttiği üzere ilkokul yıllarının kültürel mirasın aktarılmasında ve kültürel farkındalığın oluşmasında önemli görülmesidir. Bu çalışmanın bir diğer özgün noktası, fen bilimleri ders kitaplarında yer alan kültürel ögeleri belirlemek amacıyla oluşturulan ve kültürel temaları içeren bir formun hazırlanmış olmasıdır. Bu form, bundan sonraki çalışmalar için bir referans noktası oluşturması ve alana katkı sunması bakımından önem arz etmektedir.

$\mathrm{Bu}$ çalışmada aşağıdaki sorulara cevap aranmaktadır:

1. Fen Bilimleri ders kitaplarında kültürel ögeler nasıl belirlenir?

2. Fen Bilimleri ders kitaplarında hangi kültür ögeleri ön plana çıkmaktadır? 
3. Fen Bilimleri ders kitaplarında hangi üniteler daha çok kültür ögesi barındirmaktadır?

4. Millî Eğitim Bakanlığı ve özel yayınevlerinin çıkardığı ders kitaplarının kültürel ögelere yer vermesi bakımından farklılıkları var mıdır?

5. Fen Bilimleri ders kitaplarında yerel ve yabancı kültürel ögelerden ne derece yararlanılmaktadır?

\section{Yöntem}

\section{Araştırma Deseni}

Araştırmada, ilkokul 3. ve 4. sınıf fen bilimleri ders kitaplarında yer alan kültürel ögeleri tespit etmek amacıyla nitel araştırma yöntemi kullanılmıştır. $\mathrm{Bu}$ çalışmada nitel araştırma yönteminin kullanılmasının nedeni, doğrudan verinin kendisine veya kaynağına erişim imkânı sunmasından ileri gelir. Nitel araştırmalar; olay, kişi ve olguların derinlemesine incelenmesini sağlayarak betimlemeler yapılmasını, elde edilen verilerden yola çıkılarak genellemelere gidilmesini sağlar (Büyüköztürk, 2011). Çalışmada kültürel ögeleri tespit etmek amacıyla literatürden yararlanılarak ve uzman görüşleri alınarak bir form hazırlanmıştır. Bu formda dokuz tema yer almaktadır. Bunlar: "Yerel Yapılar ve Kurumlar", "Farklı Kültürlere Ait Yapılar ve Kurumlar", "Yabanc1 Bilim İnsanları ve Düşünceleri”, "Türk-İslam Bilim İnsanları ve Düşünceleri”, "El Sanatları", "Aletler, Araç-Gereçler”, "Dinî İnançlar, Semboller ve Değerler", "Sözlü Gelenek ve Anlatımlar" ve "Kültürel Yiyecekler, İçecekler".

\section{Çalışma Grubu}

Çalışmada ilkokul 3. sınıf için Millî Eğitim Bakanlığı tarafından okullara tavsiye edilen iki yayınevinin kitaplarından yararlanılmıştır. İlki, MEB Devlet Kitapları yayınevi tarafindan yayınlanan ve birinci baskısını yapan 2019 y1lı İlkokul Fen Bilimleri 3 Ders Kitabı'dır. İkincisi ise Tuna Matbaacılık tarafindan 2019 yılında çıkartılan İlkokul Fen Bilimleri 3 Ders Kitabı'dır. Çalışmada ilkokul 4. sınıf için Millî Eğitim Bakanlığı tarafından okullara tavsiye edilen iki yayınevinin kitaplarından yararlanılmıştır. İlki, MEB Devlet Kitapları yayınevi tarafindan yayınlanan ve ikinci baskısını yapan 2019 yılı İlkokul Fen Bilimleri Ders Kitabı 4'tür. İkincisi ise Suripekyolu Yayıncılık tarafından 2019 y1lında çıkartılan İlkokul Fen Bilimleri 4 Ders Kitabı'dır. 


\section{Veri Toplama Araci}

Araştırmada verilerin elde edilmesi ve yorumlanmasında doküman analizi kullanılmıştır. Doküman analizi; basılı ya da elektronik tüm belgeleri incelemek, analiz etmek ve değerlendirmek için kullanılan bir yöntemdir (Kıral, 2020). Doküman analizi aşamasında araştırmacı, amacına uygun kaynakları bulur, bunları dikkatli bir şekilde okur, gerekli olanları notlandırır ve bu notlardan yola çıkarak çıkarımlarda bulunur (Çepni, 2007). Kıral'a (2020) göre ise verilerin analizi, dokümanlara ulaşılması ve seçilmesiyle başlar. Ardından dokümanın orijinalliği kontrol edilir sonra içerik analizine geçilir. İçerik analizinde de kategoriler veya temalar oluşturulur. Dokümandaki sözcük, cümle, görsel, içerik, karakter vb. belirlenir ve ilgili temanın altına yerleştirilir. Araştırmacı, araştırmanın içeriğine göre bu değerleri sayısallaştırabilir, yüzde ve frekans şeklinde belirtebilir. Bu çalışmada da Fen Bilimleri ders kitaplarında yer alan metinler, hikâyeler, görseller, biyografiler, olaylar, sanatlar, aletler, yapılar içerik analizine tabi tutularak analiz edilmiştir.

\section{Verilerin Analizi}

Ders kitaplarında yer alan kültürel ögelerin belirlenmesi amacıyla "Yerel Yap1lar ve Kurumlar", "Farklı Kültürlere Ait Yapılar ve Kurumlar", "Yabancı Bilim İnsanları ve Düşünceleri”, "Türk-İ́slam Bilim İnsanları ve Düşünceleri”, "El Sanatlarr", "Aletler, Araç-Gereçler", "Dinî İnançlar, Semboller ve Değerler", "Sözlü Gelenek ve Anlatımlar" ve "Kültürel Yiyecekler, İçecekler" temalarını içeren bir form hazırlanmıştır. Formun hazırlanmasında literatürden faydalanılmış (Özkan-Köse ve Yüksel, 2019; Pehlivan ve Kolaç, 2016; UNESCO, 2020) ayrıca kültürler arası karşılaştırmaya imkân sunması ve Türk kültürünü yansıtması bakımından bazı temaların belirlenmesi amacıyla da bir Eğitim Uzmanı ile bir Sosyoloğun görüşlerinden yararlanılmıştır. Fen Bilimleri ders kitaplarındaki ünitelerin tüm sayfaları incelenerek burada yer alan kültürel ögelerin hangi tema altında olduğu işaretlenerek tasnif edilmiştir. Belirlenen temaların altına yerleştirilen kültürel ögeler, bu iki uzmanın da görüşleri dikkate alınarak yapılmıştır. Böylelikle her aşaması kontrollü bir şekilde gerçekleştirilen araştırmanın hem güvenirlik hem de geçerliliği sağlanmıştır. Daha sonra bunları sayısallaştırmak ve karmaşıklığını gidermek amacıyla betimsel analiz kullanılmıştır (Özgüven, 1994). Elde edilen veriler, frekans tabloları şeklinde görselleştirilmiştir. Böylelikle kültürel ögelere ait içerikler belirlenerek bunlar tablolar hâlinde sayısallaştırılmıştır. 


\section{Bulgular}

$\mathrm{Bu}$ çalışmada ilkokul ders kitaplarında kullanılan kültürel ögeler incelenmiştir. Bu bağlamda 3. ve 4. sınıf Fen Bilimleri ders kitapları incelenmiştir. Bu kitaplarda yer alan kültürel değerler; "Yerel Yapılar ve Kurumlar", "Farklı Kültürlere Ait Yapılar ve Kurumlar", "Yabancı Bilim İnsanları ve Düşünceleri”, “Türk-İslam Bilim İnsanları ve Düşünceleri”, "El Sanatları”, "Aletler, AraçGereçler", "Dinî İnançlar, Semboller ve Değerler", "Sözlü Gelenek ve Anlatımlar" ve "Kültürel Yiyecekler, İçecekler" başlıkları altında incelenmiştir.

Fen Bilimleri ders kitaplarında yer alan kültürel ögelerin ünitelere ve sınıflara göre dağılımı Tablo 1 ve 2'de verilmiştir.

\begin{tabular}{lll}
\hline Tablo 1: 3. Sınıf Ünitelerine Göre Kültürel Ögelerin Sayısı & & \\
\hline Sınıf/Yayınevi & 3. Sınıf & Tuna Yay \\
\hline Ünite Adı & MEB Yay & 12 \\
\hline Gezegenimizi Tanıyalım & 17 & 5 \\
\hline Beş Duyumuz & 10 & 6 \\
\hline Kuvveti Tanıyalım & 8 & 4 \\
\hline Maddeyi Tanıyalım & 10 & 7 \\
\hline Çevremizdeki Işık ve Sesler & 7 & 8 \\
\hline Canlılar Dünyasına Yolculuk & 4 & 6 \\
\hline Elektrikli Araçlar & 2 & $\mathbf{4 8}$ \\
\hline Toplam & $\mathbf{5 8}$ &
\end{tabular}

Tablo 1'e göre MEB ders kitabındaki kültürel ögeler (58 adet), Tuna Yayınlarının ders kitabındaki kültürel ögelerden (48 adet) daha yüksektir. Diğger taraftan en çok kültürel ögenin bulunduğu ünite ise her iki ders kitabında da "Gezegenimizi Tanıyalım” ünitesidir. En az kültürel ögenin bulunduğu ünite Tuna Yayınlarında "Maddeyi Tanıyalım" ünitesi, MEB Yayınlarında ise "Elektrikli Araçlar" ünitesidir.

Tablo 2: 4. Sınıf Ünitelerine Göre Kültürel Ögelerin Sayısı

\begin{tabular}{lll}
\hline Sınıf/Yayınevi & 4. Sınıf & \\
\hline Ünite Adı & MEB Yay & Suripekyolu Yay \\
\hline Yer Kabuğu ve Dünya'mızın Hareketleri & 14 & 16 \\
\hline Besinlerimiz / Canlılar ve Yaşam & 8 & 6 \\
\hline Kuvvetin Etkileri / Fiziksel Olaylar & 2 & 5 \\
\hline Maddenin Özellikleri & 7 & 3 \\
\hline
\end{tabular}




\begin{tabular}{lll}
\hline Aydınlatma ve Ses Teknolojileri & 15 & 13 \\
\hline İnsan ve Çevre & 7 & 1 \\
\hline Basit Elektrik Devreleri & 2 & 1 \\
\hline Toplam & $\mathbf{5 5}$ & $\mathbf{4 5}$ \\
\hline
\end{tabular}

Tablo 2'ye göre MEB ders kitabındaki kültürel ögeler (55 adet), Suripekyolu Yayınlarının ders kitabındaki kültürel ögelerden (45 adet) daha yüksektir. Diğer taraftan en çok kültürel ögenin bulunduğu ünite MEB Yayınlarında "Aydınlatma ve Ses Teknolojileri" ünitesi, Suripekyolu Yayınlarında ise "Yer Kabuğu ve Dünya'mızın Hareketleri” ünitesidir. En az kültürel ögenin bulunduğu üniteler ise MEB Yayınlarında "Kuvvetin Etkileri/Fiziksel Olaylar" ile "Basit Elektrik Devreleri" üniteleri, Suripekyolu Yayınlarında ise "İnsan ve Çevre" ile "Basit Elektrik Devreleri” üniteleridir.

Tablo 1 ve 2 birlikte incelendiğinde her ikisinde de MEB Yayınlarının ders kitaplarındaki kültürel ögelerin sayısının daha fazla olduğu görülmektedir. Diğer taraftan "Gezegenimizi Tanıyalım" ve "Yer Kabuğu ve Dünya'mızın Hareketleri” ünitesi her iki sınıf seviyesinde ve yayınevinde en çok kültürel ögenin kullanıldığı üniteler olmuştur. Diğer taraftan "Elektrikli Araçlar" ve "Basit Elektrik Devreleri" üniteleri her iki sınıf seviyesinde ve yayınevinde en az kültürel ögenin bulunduğu üniteler olmuştur.

Tablo 3: İlkokul 3. Sınıf Ders Kitaplarında Yer Alan Kültürel Değerlerin Dağılımı

\begin{tabular}{lll}
\hline Sinıf/Yayınevi & 3. Sinıf \\
\hline Ünite Adı & MEB Yay & Tuna Yay \\
\hline Yerel Yapılar ve Kurumlar & 16 & 13 \\
\hline Farklı Kültürlere Ait Yapılar ve Kurumlar & 1 & 0 \\
\hline Yabancı Bilim İnsanları ve Düşünceleri & 7 & 6 \\
\hline Türk-İslam Bilim İnsanları ve Düşünceleri & 3 & 1 \\
\hline El Sanatları & 12 & 11 \\
\hline Aletler, Araç-Gereçler & 9 & 8 \\
\hline Dinî İnançlar, Semboller ve Değerler & 7 & 9 \\
\hline Sözlü Gelenek ve Anlatımlar & 3 & 0 \\
\hline Kültürel Yiyecekler, İçecekler & 0 & 0 \\
\hline Toplam & $\mathbf{5 8}$ & $\mathbf{4 8}$ \\
\hline
\end{tabular}

Tablo 3’te görüldüğü üzere 3. sinıflarda "Yerel Yapılar ve Kurumlar", "El Sanatları" ve "Aletler, Araç-Gereçler" kültürel ögeleri ön plana çıkmaktadır. Fen Bilimleri 3. sınıf ders kitaplarında görünen en az kültürel ögeler olarak ise 
"Farklı Kültürlere Ait Yapılar ve Kurumlar", "Türk-İslam Bilim İnsanları ve Düşünceleri”, "Sözlü Gelenek ve Anlatımlar" ile "Kültürel Yiyecekler, İçecekler" göze çarpmaktadır.

Tablo 4: İlkokul 4. Sınıf Ders Kitaplarında Yer Alan Kültürel Değerlerin Dağılımı

\begin{tabular}{lll}
\hline Sınıf/Yayınevi & 4. Sınıf & \\
\hline Ünite Adı & MEB Yay & Suripekyolu Yay \\
\hline Yerel Yapılar ve Kurumlar & 9 & 5 \\
\hline Farklı Kültürlere Ait Yapılar ve Kurumlar & 0 & 2 \\
\hline Yabancı Bilim İnsanları ve Düşünceleri & 12 & 4 \\
\hline Türk-İslam Bilim İnsanları ve Düşünceleri & 0 & 0 \\
\hline El Sanatları & 4 & 4 \\
\hline Aletler, Araç-Gereçler & 17 & 20 \\
\hline Dinî İnançlar, Semboller ve Değerler & 6 & 3 \\
\hline Sözlü Gelenek ve Anlatımlar & 3 & 4 \\
\hline Kültürel Yiyecekler, İçecekler & 4 & 3 \\
\hline Toplam & $\mathbf{5 5}$ & $\mathbf{4 5}$ \\
\hline
\end{tabular}

Tablo 4'te görüldüğü üzere 4. sinıflarda "Aletler, Araç-Gereçler", "Yabanc1 Bilim İnsanları ve Düşünceleri" ile "Yerel Yapılar ve Kurumlar" ön plana çıkmaktadır. Fen Bilimleri 4. sınıf ders kitaplarında görünen en az kültürel ögeler olarak ise "Farkl1 Kültürlere Ait Yapılar ve Kurumlar", "Türk-İslam Bilim İnsanlar1 ve Düşünceleri”, "Sözlü Gelenek ve Anlatımlar" ile "Kültürel Yiyecekler, İçecekler" göze çarpmaktadır.

Tablo 3 ve Tablo 4 birlikte değerlendirildiğinde "Aletler, Araç-Gereçler" ve "Yerel Yapılar ve Kurumlar" kültürel ögelerinin Fen Bilimleri ders kitaplarında en çok kullanılan kültürel ögeler olduğu görülmektedir. En az kültürel ögeler olarak kullanılanlar ise "Farklı Kültürlere Ait Yapılar ve Kurumlar" ile “Türk-İslam Bilim İnsanları ve Düşünceleri” kültürel ögeleridir.

\section{Tartışma, Sonuç ve Öneriler}

İlkokul fen bilimleri ders kitaplarında yer alan kültürel ögelerin belirlenmesi amacıyla yapılan bu çalışmada, farklı başlıklarda kültürel ögelerin varlığı tespit edilmiştir. Kültürel ögelerin ders kitaplarında kullanılması, eğitimin kültürel mirasın aktarıcısı konumunda görülen en önemli aktörlerden birisi olmasından kaynaklanır (Akyüz, 2016; Gretta, 2001; Eroğlu ve Yaldız, 2006; Selanik-Ay ve Korkmaz, 2017; Çengelci, 2012; Türkyılmaz, 2013). Ancak kültürel ögelerin 
özellikle ilkokullarda sosyal bilgiler üzerine hasredilmesi ve fen bilimleri konusunda çalışmalara rastlanmaması ilginçtir. Çünkü eğitim, bir bütün olarak kültürün inşasında ve aktarımında etkilidir sadece sosyal bilgiler dersine hasredilmesi de doğru değildir. Bu bağlamda literatürde Sosyal Bilgiler haricinde Müzik (Özkan-Köse ve Yüksel, 2019), Türkçe (Güfta ve Kan, 2011; Ünveren-Kapanadze, 2018), İngilizce (Ulum ve Bada, 2016) ders kitaplarının kültürel ögeler bağlamında incelenmesi yapılmışken fen bilimleri gibi ders saati açısından da önemli bir yer ihtiva eden ders kitabının incelemesinin yapılmaması düşündürücüdür. Kotluk'un (2018) da belirttiği üzere Fen Bilimleri dersinin pozitivist bir bakış açısına sahip olması, kültürün aktarıcısı olmaktan ziyade bilimsel düşüncenin öncüsü olarak görülmesi bunda etkili olabilir.

Ders kitaplarında kültürel ögelerin belirlenmesi önemli bir sorundur. Çünkü bu ögelerin belirlenmesinde, tasnif edilmesinde ve değerlendirilmesinde ders kitaplarına özel bir değerlendirme aracı bulunmamaktadır. Literatürde yapılan çalışmalar incelendiğinde ders kitaplarının kültürel olarak incelenmesi bağlamında daha çok rağbet gören ve referans alınan çalışmalardan biri UNESCO (2020) tarafindan hazırlanan Somut Olmayan Kültür Miras sinıflamasıdır. Buna göre UNESCO; "Sözlü Gelenekler ve Anlatımlar", "Gösteri Sanatları", "Toplumsal Uygulamalar, Ritüeller ve Şölenler”, "Doğa ve Evrenle İlgili Uygulamalar”, "El Sanatları Geleneği” başlığı altında 5 ana alanda bir sınıflandırma yapmaktadır. Ancak bu sınıflamanın somut kültürel ögeleri içermemesi, bir yanının eksik kaldığııı göstermektedir. Bundan dolayı hem somut hem de somut olmayan kültürel ögelerin birlikte değerlendirilmesine ihtiyaç vardır. Bu iki ayağın sağlam bir şekilde kurgulanması, ders kitaplarının kültürel açıdan incelenmesine katkıda bulunacaktır. Bu çalışmada da UNESCO'nun somut olmayan kültürel miras s1nıflaması da göz önünde bulundurularak 9'lu bir sınıflandırma yapılmıştır. Bu sınıflandırmadaki başlıklar; "Yerel Yapılar ve Kurumlar", "Farklı Kültürlere Ait Yapılar ve Kurumlar", "Yabancı Bilim İnsanları ve Düşünceleri”, "Türk-İslam Bilim İnsanları ve Düşünceleri”, "El Sanatları", “Aletler, Araç-Gereçler”, "Dinî İnançlar, Semboller ve Değerler", "Sözlü Gelenek ve Anlatımlar” ve "Kültürel Yiyecekler, İçecekler” başlıkları altında incelenmiştir. Burada yapıların ve kurumların sınıflamaya dâhil edilmesi, somut kültürel ögeler olmasından kaynaklıdır. Yine bu sınıflandırmada yerel ve yabancı ayrımının yapılması, karşılaştırma yapılmasını kolaylaştırmak amacıyladır. Diğer taraftan özel olarak dinî konulara referans olabilecek hususların belirlenmesi amacıyla "Dinî İnançlar, Semboller ve Değerler" başlığ eklenmiş ayrıca fen bilimleri için önemli konu başlıkları arasında yer alan ve kültürel değerleri de içerebilecek "Bilim İnsanları ve Düşünceleri” ile "Kültürel Yiyecekler, İçecekler” başlı̆ğ da eklenmiş- 
tir. Bunun haricinde "El Sanatları" ile "Sözlü Gelenek ve Anlatımlar" somut olmayan kültürel ögeler olarak UNESCO'nun çalışmasından da yararlanılarak çalışmaya alınmıştır.

İlkokul fen bilimleri ders kitaplarının kültürel olarak incelenmesi sonucunda MEB Yayınlarının kültürel ögeleri daha fazla içerdiği sonucuna ulaşılmıştır. $\mathrm{Bu}$ bağlamda devletin bir yayını olarak öne çıkan MEB ders kitabı, özel yayıncılığın ötesinde kültürel ögelere ders kitaplarında daha fazla yer vermektedir. Bu husus, devletin kültürel değerlere daha fazla sahip çıkılmasını, kültürü sonraki nesillere aktarma hususunda daha bilinçli olunmasını göstermesi bakımından önemlidir. Özellikle incelenen kitaplarda yerel yapılara çokça yer verilmesi ve farklı yapı ve kurumlardan ziyade yerel yapı ve kurumların seçilmesi, bu iddiay1 güçlendirmektedir. Örneğin; 3. sınıfın "Gezegenimizi Tanıyalım” ünitesinde MEB ders kitabında Anıtkabir, Van Gölü, Ağrı Dağı, Ihlara Vadisi, Sümela Manastır1, Peri Bacaları, Giresun Adası, Uzungöl, Erzincan Ovası yer alırken Tuna Yayınlarında hiç yerel resme yer verilmemiş ya da tanıtımı yapılmamıştır. Yine 4. sınıfın ilk ünitesi olan "Yer Kabuğu ve Dünya'mızın Hareketleri” ünitesinde MEB ders kitabında Pamukkale Traventerleri ve Kız Kulesi resmi verilmişken Suripekyolu Yayınlarının ders kitabında hiç yerel resme yer verilmemiştir. Bunun aksine Fransa'daki Chauvet (Çavet) Mağarası ile Amerika'daki Büyük Kanyon Ulusal Parkı'na yer verilmiştir. Tüm bu söylenenler ışığında ilkokul fen bilimleri MEB ders kitaplarında mümkün olduğunca yerel kültürümüzü tanıtacak ve resmedecek ögelere yer verilirken diğer yayınevlerinin ders kitaplarında bu hususta bir hassasiyete rastlanılmamıştır. Ders kitaplarında yerel ögelerin ön plana çıkartılması, çocukların kendi ülkelerini ve tarihlerini bilme noktasında yaşanmışlıklarını şekillendirecek bilinçli bir adımın atılmasında anahtar işlev görebilir.

İlkokul fen bilimleri ders kitapları incelendiğinde bazı ünitelerin kültürel ögeler taşıması hususunda ön plana çıktığı görülmektedir. Özellikle 3. sınıflarda “Gezegenimizi Tanıyalım” ünitesi ile 4. sınıflarda "Yer Kabuğu ve Dünya'mızın Hareketleri” ünitesi bu kapsamda değerlendirilebilir. Bu iki ünite birbirinin devamı niteliğinde olduğundan yapılacak değerlendirmeler her iki kitap için de kapsayıcı olacaktır. Bu ünitelerde kullanılan ve örneklendirilen yerlerin seçiminde ülkemiz içinden sonra da yakın coğrafyadan hareketle bazı yerlerin seçilerek ders kitaplarına yansıtılması daha uygun olabilir. Burada dikkat edilecek husus, öncelikle yerelin ön planda tutulup küresele doğru bir akışın tercih edilmesidir. Kültürel değerler bağlamında öne çıkan bir başka ünite ise 4. sınıf “Aydınlatma ve Ses Teknolojileri” ünitesidir. Bu ünitede geçmişten günümüze 
aydınlatma teknolojileri anlatılmaktadır. Bu ünite, tarihte kullanılan aletlerin/ araç-gereçlerin gelişim aşamaları yansıtması ve belli bir usul göstermesi bakımından önem arz etmektedir. Bu aletlerden/araç-gereçlerden kültürümüze ait olanların ayrıca ele alınması önemli görülmektedir.

Fen bilimleri ders kitaplarının inceleme alanlarından birini oluşturan konuların başında bilim insanları ve bilim tarihi gelmektedir. Fen bilimleri ders kitaplarındaki bilim insanlarını ve bilim tarihini inceleyen çok sayıda çalışma mevcuttur (Koçyiğit ve Pektaş, 2017; Görecek-Baybars, 2018; Laçin-Şimşek, 2009; Laçin-Şimşek, 2011b; Bayburt ve Çakırca, 2019; Sarıtaş, 2020). Bu çalışmaların çok büyük bir kısmı ise Türk-İslam bilim insanlarını araştırma konusu edinmektedir. Bu çalışmada da görüldüğü üzere Türk-İslam bilim insanlarının ilkokul fen bilimleri ders kitaplarında çok fazla bir yer edinmediği ve yer almadığı görülmektedir. Örneğin; MEB 3. sınıf kitabında 3, Tuna Yayınlarının kitabında ise 1 yerde Türk-İslam bilim insanlarından bahsedilmiş, 4. sınıf kitaplarında ise hiç bahsedilmemiş̧ir. Kültürel değerlerin önemli aktarım bileşenlerinden biri olarak görülen ve hem toplumları etkileyen hem de toplumlardan etkilenen bilim insanlarının ve bilim tarihinin ders kitaplarında yerinin çok az olduğu görülmektedir. Bu çalışmada da belirtildiği üzere kültürel değerlerin bileşimi olarak görülen “Türk-İslam Bilim İnsanları ve Düşünceleri” kültürel ögesi, ders kitaplarında yeterli derecede yer almamaktadır.

Çalışmada bir başka önemli husus ise yabancı ve Türk-İslam bilim insanlarının ders kitaplarında hangi oranlarda yer aldıkları meselesidir. Hemen hemen her alana katkıda bulunan ya da destek olan Türk-İslam bilim insanlarının varlığından söz edilebilir. Bu durum fen bilimleri dersi bağlamında daha çok ön plana çıkartılabilecek bir özelliktir. Ancak bu çalışmada da görüldüğü üzere "Yabancı Bilim İnsanları ve Düşünceleri”nden söz eden toplamda 29 öge varken bu durum Türk-İslam bilim insanlarında sadece 4'tür (3. ve 4. sınıf tüm yayınevlerinde bahsedilen bilim insanları). Bu tespit, ders kitaplarında yeterli oranda ve sayıda Türk-İslam bilim insanına yer verilmediğini göstermektedir.

İlkokul ders kitapları kültürel olarak değerlendirildiğinde konuların anlatımında bu kültüre ait farklı bileşenlerin kullanıldığı görülebilir. Örneğin; ders kitaplarında geleneksel pazaryerlerinin resminin yer alması, geleneksel oyunlara yer verilmesi (topaç, misket vs.), birçok yerde kültürün de ön plana çıktı$\breve{g} 1$ değerlerin aktarılması (tasarruf, engelli ve yaşlılara yardım vs.), geleneksel yemekleri ve içecekleri içeren görseller (limonata, ayran vb.), dinî değerlere 
verilen önem (görsellerde başörtülü kadınların kullanılması, semah gösterisi vb.) ön plandadır. Ancak bu kültürel ögelerin ders kitaplarında yeterli sayıda bulunduğunu söylemek güçtür. Literatürde de Türk kültürünü tanıtacak kültürel ögelerin ders kitaplarında yeteri kadar yer almadığı belirtilmektedir (Bayraktar, 2015; Okur, 2013; Ünveren-Kapanadze, 2018). Bu kültürel değerlerin ders kitaplarında yeterli kullanımı, çocuklara verilmek istenen kültürle yakından ilgili ve amaca yönelik olacaktır.

Tüm bu değerlendirmeler 1şığında aşağıdaki önerilere yer verilmiştir:

- İlkokul Fen Bilimleri ders kitaplarının farklı kültürel ögeler bakımından değerlendirilmesi sağlanabilir.

- Farklı çalışmalarla Fen Bilimleri ders kitaplarını kültürel ögeler açısından değerlendiren formun geliştirilmesi sağlanabilir.

- Ders kitapları hazırlanırken öncelikli olarak ünitelerde yerel mekânlar tercih edilebilir.

- Ders kitaplarında görsellerin ve ögelerin seçiminde yereli yansıtan ve Türk kültürüne daha yakın görsellerin seçilmesi sağlanabilir.

- Ders kitaplarında geçmişten günümüze kadar geliştirerek kullandığımız aletlerin seçiminde kültürel ögeleri barındıran aletler hakkında ayrıca bir bilgilendirme yapılabilir.

- Ders kitaplarında Türk-İslam bilim insanlarının görsellerinden ve düşüncelerinden faydalanılabilir.

\section{Kaynakça}

Acar, B. ve Yaman-Kasap, M. (2020). Review of the values in biology textbooks of secondary education. Sakarya University Journal of Education, 10(2), 336-349.

Akyüz, Y. (2016). Eğitimin kültür ve uygarlıkları geliştirme ve yeni nesillere aktarma işlevi. Türkiye Ĕgitim Dergisi, 1(1), 1-18.

Arslanoğlu, İ. (2015). Genel sosyoloji-ders notları. Gazi Yayınevi.

Ateş, S., İncirci, A., Karadeniz, O. ve Kapucubaş, M. (2018). Sosyal bilgiler ders kitaplarında eski Türkler: Türkiye ve Türkmenistan. Uluslararası Sosyal Bilgilerde Yeni Yaklaşımlar Dergisi, 2(1), 70-85.

Aybey, S. (2018). Ailenin dini değerleri aktarmadaki rolü ve bu süreçte dikkat edilmesi gereken ilkeler. Insan ve Toplum Bilimleri Araştırmaları Dergisi, $7(2), 544-560$. 
Baş, R. F. (2019). Fen bilgisi öğretmen adaylarının bilim tarihi algısına bilimin sultanları sergisinin etkisi (Yayımlanmamış yüksek lisans tezi). Hacettepe Üniversitesi, Eğitim Bilimleri Enstitüsü, Anakara.

Bauman, Z. (2020). Eğitim üzerine. A. E. Pilgir (Çev.). Ayrıntı Yayınları.

Bayburt, B. ve Çakırca, P. (2019, Aralık). Türkiye'de ortaokul 5, 6 ve 7. Sınıf sosyal bilgiler programlarında bilim tarihi üzerine değerlendirme. VI. Yıldız Uluslararası Sosyal Bilimler Sempozyumu'da sunulan bildiri, Yıldız Teknik Üniversitesi, İstanbul. http://www.sbe.yildiz.edu.tr/media/files/7_\%20 YSBK\%20Bildiri\%20\%C3\%96zetleri\%20Kitab\%C4\%B1\%20v3.pdf

Bayraktar, S. (2015). Yeni Hitit 1 yabancılar için Türkçe ders kitabının kültür aktarımı açısından incelenmesi. Hacettepe Üniversitesi Yabancı Dil Olarak Türkçe Araştırmaları Dergisi, 2, 7-23.

Bozdoğan, B., Şengül, Ü. ve Bozdoğan, A. E. (2013). Fen bilgisi öğretmen adaylarının bilim insanları hakkındaki bilgi düzeylerinin incelenmesi: Giresun Eğitim Fakültesi örneği. Karadeniz Sosyal Bilimler Dergisi, 5(9).

Büyüköztürk, Ş. (2011). Sosyal bilimler için veri analizi el kitabı. Pegem Akademi Yayınları.

Çengelci, T. (2012). Sosyal bilgiler öğretim programında somut olmayan kültürel mirasın yeri. Uludă̆ Üniversitesi Eğitim Fakültesi Dergisi, 25(1), 185-203.

Çepni, S. (2007). Araştırma ve proje çalışmalarına giriş. Celepler Matbaacılık.

Daşdemir, İ. ve Tekin, S. (2018). Sosyal bilgiler ders kitaplarında Türk-kültür öğelerinin kullanımı. Türk Dünyası Incelemeleri Dergisi, 18(1), 215-228.

Demir, S. B. ve Akengin, H. (2014). Hikâyelerle sosyal bilgiler ögretimi (3. Bask1). PEGEM Akademi.

Demirel, Ö. (2003). Planlamadan değerlendirmeye öğretme sanatı. PegemA Yayıncilik.

Doğan, C. (2019). Kültürel olguların masallarda aktarımı ve çevirinin önemi. H. Asutay, E. Jable, D. Y. Ergin ve Ç. Karaoğlu-Bircan (Ed.). Çocuk ve gençlik yazınında çokkültürcülük içinde (ss. 29-36). Trakya Üniversitesi Yayınları.

Dönmez, C. ve Yeşilbursa, C. C. (2014). Kültürel miras eğitiminin öğrencilerin somut kültürel mirasa yönelik tutumlarına etkisi. Ilköğretim Online, 13(2), 425-442.

Drakopoulou, M., Skordoulis, C. ve Halkia, K. (2005). History of science in 20th century Greek science textbooks of primary education. Proceedings International History, Philosophy and Science Teaching Conference içinde (s. 12). Leeds, England.

Egüz, Ş. ve Kesten, A. (2012). Sosyal bilgiler dersinde müze ile eğitimin öğretmen ve öğrenci görüşlerine göre değerlendirilmesi: Samsun ili örneği. İnönü Üniversitesi Ĕ̆itim Fakültesi Dergisi, 13(1), 81-104. 
Ergin, D. Y. ve Çayak, S. (2019). Veli Beklentileri Ölçeği’nin geçerlik ve güvenirlik çalışması. Balkan ve Yakın Doğu Sosyal Bilimler Dergisi, 5(2), 46.

Eroğlu, B. ve Yaldız, E. (2006). Kültür mirasının sürekliliği için anıtsal binaların yeniden kullanılması bağlamında Ermenek Tol Medrese. Selçuk Üniversitesi Sosyal Bilimler Enstitüsü Dergisi, 15, 315-340.

Erol, N. (2011). Toplumsal değişme ve eğitim: Temel ilişkiler, çelişkiler, tartışmalar. Gazi Akademik Bakış Dergisi, 5(9), 109-122.

Fazlıoğlu, İ. (2004). İki ucu müphem bir köprü: Bilim ile tarih ya da bilim tarihi. Türkiye Araştırmalarl Literatür Dergisi, 2(4), 9-27.

Fer, S. (2019). Eğitimde program geliştirme. PEGEM Akademi.

Gadamer, H. G. (1988). On the circle of understanding hermeneutics versus science? J. M. Connolly ve T. Keutner (Çev.). University of Notre Dame Press.

Gökçe, B. (1990). Aile ve aile tipleri üzerine bir inceleme. B. Dikeçligil ve A. Çiğdem (Der.). Aile yazıları I, temel kavramlar yapı ve tarihi süreç içinde (ss. 205-223). T.C. Başbakanlık Aile Araştırma Kurumu.

Görecek-Baybars, M. (2018). Fen bilgisi öğretmen adaylarının bilim insanı farkındalıklarının belirlenmesi. Trakya Eğitim Dergisi, 3(8), 564-577.

Gretta, K. N. (2001). A critical analysis of multicultural education with special referance to the values issue in the South African context (Yayınlanmamış Yüksek Lisans Tezi). Güney Afrika Üniversitesi, Eğitim Fakültesi, Pretoria.

Güfta, H. ve Kan, M. (2011). İlköğretim 7. sınıf Türkçe ders kitabının dil ile ilgili kültür ögeleri açısından incelenmesi. Mustafa Kemal Üniversitesi Sosyal Bilimler Enstitüsü Dergisi, 8(15), 239-256.

Gülden, B. (2018). Türkçe ders kitaplarında kültür temelli hazırlanan etkinlikler üzerine bir inceleme (5. sınıf Türkçe ders kitabı örneği). Turkish Studies, 13(11), 1635-1652.

Gün-Duru, E. (2013). Türk müzik kültürünün genel müzik eğitimine yansımalar1. The Journal of Academic Social Science Studies, 6(5), 587-96.

Gündüz, M., Aktepe, V., Sulak, S. E., Başpınar, Z. ve Büyükkarcı, A. (2019). Cultural values defining Turkish nation: From the perspectives of history teachers. International Journal of Instruction, 12(2), 193-208.

Güngör, E. (1994). Kültür değişmesi ve milliyetçilik. Ötüken Neşriyat.

Gürel, D. ve Çetin, T. (2018). Sosyal bilgiler dersi ve kültür aktarımında edindiği rol üzerine bir inceleme. Anadolu Ĕ̈itim Liderliği ve Öğretim Dergisi, 6(2), 22-40.

Gürses, A., Açıkyıldız, M., Bayrak, R., Yalçın, M. ve Doğar, Ç. (2004). Fen eğitimi: Kültürel bir bakış. Kastamonu Eğitim Fakültesi Dergisi, 12(1), 31-40. 
Heine, S. J. (2008). Cultural psychology. Norton.

İdin, Ş. ve Yalaki, Y. (2016). Türkiye'deki ortaokul fen bilimleri ders kitaplarında yer verilen Türk-İslam bilim insanlarının incelenmesi. Yaşadıkça Eğitim, $30(2), 37-52$.

İşeri, A. (2020). Küresel beceriler ve ders kitaplarına yansıması. Türk Eğitim Bilimleri Dergisi, 18(1), 296-325.

Kaplan, M. (2010). Kültür ve dil (26. Bask1). Dergâh Yayınları.

Kardaş, S. ve Şahin, F. (2020). Bilimsel hikâyelerin 6. sınıf öğrencilerinin akademik başarılarına ve bilimin doğasını anlamalarına etkisinin incelenmesi. IBAD Sosyal Bilimler Dergisi, 7, 222-234.

Karışan, D. (2017). Fen teknoloji toplum çevre (FTTÇ) öğretimi. M. P. Demirci-Güler (Ed.). Fen bilimleri ögretimi içinde (ss. 76-89). PEGEM Akademi.

Kiral, B. (2020). Nitel bir veri analizi yöntemi olarak doküman analizi. Siirt Üniversitesi Sosyal Bilimler Enstitüsü Dergisi, 8(15), 170-189.

Koçyiğit, A. ve Pektaş, M. (2017). Ortaokul fen bilimleri ders kitaplarındaki okuma parçalarının bilim tarihi kullanımı açısından incelenmesi. Cumhuriyet Uluslararası Eğitim Dergisi, 6(1), 185-199.

Kongar, E. (1982). Kültür üzerine. Çağdaş Yayınları.

Kotluk, N. (2018). Kültürel değerlere duyarlı eğitime ilişkin öğretmenlerin öz-yeterlik algılarının ve görüşlerinin incelenmesi. (Yayımlanmamış Doktora Tezi). Yüzüncü Yıl Üniversitesi, Eğitim Bilimleri Enstitüsü, Van.

Kotluk, N. ve Kocakaya, S. (2018). Türkiye için alternatif bir anlayış: Kültürel değerlere duyarlı eğitim. Yüzüncü Yıl Üniversitesi Eğitim Fakültesi Dergisi, 15(1), 749-789.

Laçin-Şimşek, C. (2009). Fen ve teknoloji dersi öğretim programları ve ders kitapları bilim tarihinden ne kadar ve nasıl yararlanıyor? Ilköğretim Online, 8(1), 129-145.

Laçin-Şimşek, C. (2011a). Science and technology teachers' situation of integrating history of science into their lessons. International Online Journal of Educational Sciences, 3(2), 707-742.

Laçin-Şimşek, C. (2011b). Fen ve teknoloji dersi öğretim programı ve kitaplarında Türk-İslam bilginlerine yer verilme durumu. Türk Fen Eğitimi Dergisi, 8(4), 154-168.

MEB. (2018). Sosyal bilgiler dersi öğretim programı (2020, Ekim 11) http://mufredat.meb.gov.tr/Dosyalar/201812103847686SOYAL\%20 B\%C4\%B0LG\%C4\%B0LER \%20\%C3\%96\%C4\%9ERET\%C4\%B0M\%20 PROGRAMI\%20.pdf 
Meydan, A. ve Akkuş, A. (2014). Sosyal bilgiler öğretiminde müze gezilerinin tarihi ve kültürel değerlerin kazandırılmasındaki önemi. Marmara Coğrafya Dergisi, 29, 402-422.

Okur, A. (2013). Millî kültür ve folklorun Türkçe ders kitapları aracılığıyla aktarımı. Adıyaman Üniversitesi Sosyal Bilimler Enstitüsü Dergisi Türkçenin Eğitimi Öğretimi Özel Sayısı, 6(11), 877-904.

Özdemir, N. (2019). Kuşaklararasılık ve kültürel değişme. Çocuk ve Medeniyet, 1, 125- 149.

Özgüven, İ. E. (1994). Psikolojik testler. Yeni Doğuş Matbaası.

Özkan-Köse, P. ve Yüksel, A. L. (2019). 5, 6, 7 ve 8. sınıf müzik ders kitaplarının somut olmayan kültürel miras öğeleri bakımından incelenmesi. Art-e Sanat Dergisi, 12, 125-149.

Öztürk, C., Keskin, S. C. ve Otluoğlu, R. (2014). Sosyal bilgiler ögrretiminde edeb̂̂ ürünler ve yazılı materyaller (6. Bask1). PEGEM Akademi.

Pass, S., White, J., Owens, E. ve Weir, J. (2006). Bringing cultures into the classroom: An invitation to families. Social Studies and the Young Learner, 19(2), 16-18.

Pehlivan, A. ve Kolaç, E. (2016). Açık-örgün eğitim sosyal bilgiler ders kitapları ve öğretim programında somut olmayan kültürel miras ögeleri. Turkish Studies, 11(19), 655-670.

Safran, M. (2008). Sosyal bilgiler öğretimine bakış. B. Tay ve A. Öcal (Ed.). Özel öğretim yöntemleriyle sosyal bilgiler ögretimi içinde (ss. 2-16). PEGEM Akademi.

Sağ, Ç. (2018). Illkokul sosyal bilgiler dersinde somut olmayan kültürel miras eğitimine yönelik etkinlik temelli bir eylem araştırması. (Yayımlanmamış Yüksek Lisans Tezi). Bartın Üniversitesi, Eğitim Bilimleri Enstitüsü, Bartın.

Sarıtaş, D. (2020). Güncel fen bilimleri öğretim programının bilim-kültür-bilim tarihi ilişkisi açısından incelenmesi ve uygun bir ilişki için kuramsal öneriler. Eğitimde Yeni Yaklaşımlar Dergisi, 3(1), 28-38.

Selanik-Ay, T. ve Korkmaz, Ç. (2017). Sosyal bilgiler programında yer alan değerler ve kültürel ögeler bağlamında "Küçük Hezarfen” çizgi filmi. Batı Anadolu Eğitim Bilimleri Dergisi, 8(2), 49-62.

Sönmez, Ö. F. (2014). Atasözlerinin sosyal bilgiler programındaki değerler açısından incelenmesi. Zeltschrlft Für Dıe Welt Der Türken, 6(2), 101-115.

Sülün, A. ve Balkı, N. (2008). Türkiye'de fen ve teknoloji eğitimi ve kültür. Erzincan Üniversitesi Fen Bilimleri Enstitüsü Dergisi, 1(1), 85-98.

Şahin, F. T. ve Kalburan, F. N. C. (2009). Aile eğitim programları ve etkililiği: Dünyada neler uygulanıyor? Pamukkale Üniversitesi Eğitim Fakültesi Dergisi, 25(25), 1-12. 
Şahin, M. (2019). Kültür değişimleri ve eğitim. Eğitim Kuram ve Uygulama Araştırmalarl Dergisi, 5(3), 458-466.

TDK. (2020). “Kültür”. Türk Dil Kurumu.

Topçu, N. (2013). Yarınki Türkiye. Dergâh Yayınları.

Toran, M. ve Özgen, Z. (2018). Okul öncesi eğitimde aile katılımı: Öğretmenler ne düşünüyor, ne yapıyor? Eğitimde Nitel Araştırmalar Dergisi, 6(3), 229-245.

Turhan, M. (2002). Kültür değişmeleri-sosyal psikoloji bakımından bir tetkik. Çamlıca.

Türkyılmaz, D. (2013). Somut olmayan kültürel miras çalışmaları bağlamında TÜRKSOY bölgesel seminerlerine ilişkin bir değerlendirme. Milli Folklor Dergisi, 100, 40-49.

Ulum, Ö. G. ve Bada, E. (2016). Cultural elements in EFL course books. Gaziantep Üniversitesi Sosyal Bilimler Dergisi, 15(1), 15-26.

UNESCO. (1982). Mexico city declaration on cultural policies (2020, Ekim 10). http://portal.unesco.org/culture/en/files/12762/11295421661mexicoen.pdf/ mexico_en.pdf

UNESCO. (2020). What is intangible cultural heritage? (2020, Ekim 10). https:// ich.unesco.org/en/what-is-intangible-heritage-00003.

Ültanır, G. (2003). Eğitim ve kültür ilişkisi-eğitimde kültürün hangi boyutlarının genç kuşaklara aktarılacağı kaygısı. Gazi Eğitim Fakültesi Dergisi, 3(23), 3291-309.

Ünlüer, G. (2018). Sosyal bilgiler dersinde kültür öğretiminde türkülerden yararlanma. Hitit Üniversitesi Sosyal Bilimler Enstitüsü Dergisi, 11(1), 581-594.

Ünveren-Kapanadze, D. (2018). Dil ve kültür aktarımında işlevsel bir araç olarak ders kitapları: Türkçe ders kitapları örneği. Turkish Studies Educational Sciences, 13(27), 1575-1592.

Varış, F. (1994). Eğitimde program geliştirme teori ve teknikleri. Alkım Kitapçılık Yayıncilik.

Yalaki, Y. (2014). Türkiye'de fen, teknoloji, toplum, çevre (FTTÇ) eğitimi ne durumda? Cito Eğitim: Kuram ve Uygulama, 26, 27-36. 
Extended Abstract

\title{
Examination of Cultural Elements in Primary School Science Textbooks
}

\author{
M. Fatih GÜVENDİ, Corresponding Author, Ph.D. Student. \\ Marmara University, Institute of Educational Sciences, Istanbul/Türkiye. \\ fatihguvendi@marun.edu.tr \\ https://orcid.org/0000-0002-3355-040X
}

Article Type: Research Article

https://doi.org/10.34234/ded.895236

Received Date: 11.03 .2021

Accepted Date: 09.08.2021

Published Date: 25.12.2021

\section{Introduction}

Education plays a major role in the transmission of social values as well as the development of individuals' cognitive knowledge and skills (Acar \& YamanKasap, 2020). Social values brought from the past through education are transferred to future generations, taking into account the needs of the present. Material and spiritual cultural heritage from the past is decisive in the formation and transfer of social values (Acar \& Yaman-Kasap, 2020; Gündüz et al., 2019). The separation of culture as material and spiritual (Turhan, 2002) stems from the definition of culture as a way of life (Varış, 1994). Accordingly, material culture; consists of a society's food, the goods it wears, the tools it uses, its architectural structure, handicrafts and similar components. The spiritual di- 
mension of culture is defined as the religion, language, customs and traditions, value judgments, literature, art, science and philosophy (Arslanoğlu, 2015). Although Kongar (1982) excludes the world of literature, art and thought from this classification, they count them among the important components of culture. On the other hand, Güngör (1994) argues that culture is a set of beliefs, knowledge, feelings and emotions. In addition, he states that material culture is not culture in itself and sees material culture as a form of expression of spiritual culture. Contrary to Güngör's (1994) definition, Gadamer (1988) interprets culture mostly through life practices, that is, material culture. Topçu (2013) also sees culture as the overall value judgments that society creates by reading through its own historical adventure. On the other hand, UNESCO defines culture in the Final Declaration of the World Conference on Cultural Policies as follows; "Culture, in its broadest sense, is a collective phenomenon, made up of the distinctive material, spiritual, mental and emotional characteristics that define a society or social group, and encompasses not only science and literature but also lifestyles, fundamental human rights, values, traditions and beliefs" (UNESCO, 1982).

There is no study in Turkey that includes examining science textbooks in a cultural context. Thus, the novelty and the motivation of this study largely rely on this gap in the literature. In this context, the aim of this study is to determine the cultural elements in primary school science textbooks. The reason for choosing primary school textbooks in this study is that primary school years are considered important in transferring cultural heritage and creating cultural awareness, as stated by Çengelci (2012) and Pass et al. (2006). Another novelty of this study is that a form including cultural themes was prepared to determine the cultural elements in Science textbooks. This issue is important in terms of creating a reference point for future studies and contributing to the field.

\section{Method}

In the research, document analysis, one of the qualitative research methods, was used to determine the cultural elements in the primary school science textbooks for 3rd and 4th grades. The document analysis method is used to examine, analyze and evaluate all printed or electronic documents (Kiral, 2020). In the document analysis process, the researcher finds the appropriate sources, reads them carefully, notes the necessary ones, and makes inferences based on these notes (Çepni, 2007). According to Kıral (2020), the analysis of the data starts with accessing and selecting the documents. Then the originality of the document is 
checked and content analysis is started. In content analysis, categories or themes are created. Word, sentence, image, content, character, etc. in the document determined and placed under the relevant theme. The researcher can digitize these values according to the content of the research and indicate them as percentages and frequencies. In this study, texts, stories, images, biographies, events, arts, tools, structures in Science textbooks were analyzed by content analysis.

In order to determine the cultural elements in the textbooks, a form containing the following themes was prepared: "Local Structures and Institutions", "Structures and Institutions Belonging to Different Cultures", "Foreign Scientists and Their Thoughts", "Turkish-Islamic Scientists and Thoughts", "Handicrafts", "Tools and Equipments", "Religious Beliefs, Symbols and Values", "Oral Traditions and Expressions" and "Cultural Foods, Beverages". In the preparation of the form, the literature was used (Özkan-Köse \& Yüksel, 2019; Pehlivan \& Kolaç, 2016; UNESCO, 2020), and the opinions of an Educational Specialist and a Sociologist were applied to identify some themes in order to allow cross-cultural comparison and reflect Turkish culture. All pages of the units in the science textbooks were examined and the cultural elements included here were classified under the relevant theme. The classification of the cultural elements under the determined themes were made in accordance with the opinions of the aforementioned two experts. In this way, both the reliability and validity of the research, whose every stage was carried out in a controlled manner, was provided.

\section{Findings}

It is seen that the number of cultural elements in the textbooks of MEB Publications is higher. On the other hand, the units "Let's Get to Know Our Planet" and "The Earth's Crust and the Movements of Our Earth" were the units in which the most cultural elements were used in both grade levels and publishing houses. On the other hand, "Electric Vehicles" and "Simple Electric Circuits" units were the units which included the lowest number of cultural elements at both grade levels and in the publishing house. It is seen that the cultural elements of "Tools, and Equipments" and "Local Structures and Institutions" are where the most cultural elements in Science textbooks are used. Those that included the lowest number of cultural elements are "Structures and Institutions Belonging to Different Cultures" and "Turkish-Islamic Scientists and Thoughts". 


\section{Discussion, Conclusion and Suggestions}

This study which aimed to investigate the cultural elements in primary school science textbooks, revealed different cultural elements under different titles. The embodiment of cultural elements in textbooks stems from the fact that education is one of the most important actors seen as the transmitter of cultural heritage (Akyüz, 2016; Gretta, 2001; Eroğlu \& Yaldız, 2006; Selanik-Ay \& Korkmaz, 2017; Çengelci, 2012; Türkyılmaz, 2013). However, it is interesting that cultural elements are restricted to Social Studies, especially in primary schools, and there are no studies investigating them through science. Since education is effective in the construction and transfer of culture as a whole, the incorporation of cultural elements should not be restricted to Social Studies course. In the related literature, apart from Social Studies, Music (Özkan-Köse \& Yüksel, 2019), Turkish (Güfta \& Kan, 2011; Ünveren-Kapanadze, 2018), English (Ulum $\&$ Bada, 2016) textbooks were examined in the context of cultural elements. However, it is thought-provoking that the Science textbook, with more time and attention dedicated to the courses it is taught through, is not examined in terms of cultural elements. As Kotluk (2018) stated, the fact that the science course has a positivist perspective and that it is seen as a pioneer of scientific thought rather than being a transmitter of culture may be contribute to this.

As a result of the cultural examination of primary school science textbooks, it was concluded that MEB Publications contain more cultural elements. In this context, the MEB textbook, which stands out as a publication of the state, includes more cultural elements in the textbooks beyond private publishing. This issue is important in that it shows that the state is better at embracing cultural values more conscious about transferring culture to the next generations. In particular, the fact that local structures and institutions are included in the books examined, strengthen this claim.

When primary school textbooks are evaluated culturally, it can be seen that different components of this culture are used in the narrative of the subjects. In that regard; including pictures of traditional marketplaces in textbooks, including traditional games (topaç, marbles, etc.), conveying values in which culture is at the forefront in many places (savings, helping the disabled and the elderly, etc.), visuals containing traditional dishes and drinks (lemonade, ayran, etc.), the importance attached to religious values (the use of headscarved women in visu- 
als, semah performance, etc.) are among the most striking examples.. However, it is difficult to say that these cultural elements occurrences in the textbooks are sufficient. As the literature indicates, the cultural elements that will introduce Turkish culture are not sufficiently included in the textbooks (Bayraktar, 2015; Okur, 2013; Ünveren-Kapanadze, 2018). Adequate use of these cultural values in textbooks closely depend on the culture desired to be given to children, thus it became purposeful.

In the light of all these evaluations, the following recommendations are made:

- Primary school science textbooks can be evaluated in terms of different cultural elements.

- Forms that evaluates science textbooks in terms of cultural elements can be developed through different studies.

- Preferences should be given to local sites and locations while preparing textbooks.

- In the selection of visuals and elements in the textbooks, it can be ensured that the visuals that reflect the local and are closer to Turkish culture can be selected.

- In the selection of the tools that we have developed and used in the textbooks from the past to the present, additional information can be given about the tools that contain cultural elements.

- Visuals and thoughts of Turkish-Islamic scientists can be used in textbooks.

Etik Beyan / Ethical Statement: Bu çalışmanın hazırlanma sürecinde bilimsel ve etik ilkelere uyulduğu ve yararlanılan tüm çalışmaların kaynakçada belirtildiği beyan olunur. / It is declared that scientific and ethical principles have been followed while carrying out and writing this study and that all the sources used have been properly cited.

Finansman / Funding: Yazar, bu araştırmayı desteklemek için herhangi bir dış fon almadığını kabul eder. / The author acknowledges that he recevied no external funding in support of this research. 